\title{
Los y las jóvenes y su derecho a la planificación familiar
}

Population Council

Follow this and additional works at: https://knowledgecommons.popcouncil.org/departments_sbsr-rh How does access to this work benefit you? Let us know!

\section{Recommended Citation}

"Los y las jóvenes y su derecho a la planificación familiar," Información Jóvenes México. Mexico City: Population Council, 2005. 


\section{los y las jóvenes y su derecho a la planificación familiar}
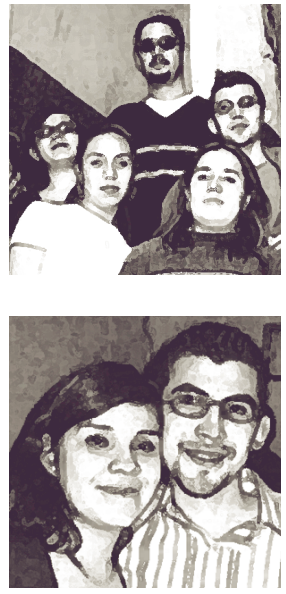

La salud reproductiva de las y los jóvenes es una cuestión global de derechos humanos porque, más allá del individuo, tiene un impacto sobre la familia,

la sociedad, la economía y la comunidad global.

\section{Referencias}

1. CONAPO, 11 de Julio Día Mundial de la Población. 2004, Consejo Nacional de Población: México. p. 13.

2. Artículo $4^{\circ}$ de la Constitución Política de los Estados Unidos Mexicanos.

3. Mexfam, Encuesta gente joven 99. 1999, Population Council, Mexfam, Frontiers: México. p. 3-5.

4. CONAPO, Serie Documentos Técnicos: Situación actual de las y los jóvenes en México. Diagnóstico sociodemográfico. 2000, Consejo Nacional de Población: México. p. 27, 56, 60, 62.

5. Demysex y CNDH, Cartilla de los Derechos Sexuales de las y los Jóvenes. 2003, Comisión Nacional de los Derechos Humanos, Red Democracia y Sexualidad, Campaña Nacional por los Derechos Sexuales de las y los Jóvenes: Hagamos un Hecho Nuestros Derechos

6. Declaración de los Derechos Sexuales de las y los Jóvenes. En: Foro Nacional de Jóvenes por los Derechos Sexuales. 2000. Tlaxcala, México: Instituto Mexicano de la Juventud, Dirección de Programas para la Juventud del Gobierno del Distrito Federal.

7. Naciones Unidas. Programa de Acción de la Conferencia Internacional sobre Población y Desarrollo, en Conferencia Internacional sobre Población y Desarrollo. 1994. Cairo, Egipto.

8. Creel, L. y R. Perry, Nuevas perspectivas sobre la calidad de la atención. No.4: Mejoras en la calidad de los servicios de salud reproductiva para los jóvenes. 2003, Population Council.

9. IMSS, Diagnóstico Cualitativo para la Elaboración de un Programa de Salud Reproductiva en Adolescentes de Áreas Rurales. 1999, Instituto Mexicano del Seguro Social: México.
El gobierno mexicano debe encargarse de mejorar el acceso de los y las jóvenes a los servicios de salud reproductiva y de otorgar la privacidad de la atención y la capacitación de los proveedores, según se establece en la Declaración de Tlaxcala:

- “...Recibir información y atención por personal sensible, respetuoso y capacitado en los temas. Conocer, tener acceso e información para el uso adecuado de toda la gama de métodos anticonceptivos y alternativas para la prevención de infecciones de transmisión sexual, VIH, embarazos no planeados o no deseados." -Declaración de los derechos de los jóvenes mexicanos, desarrollada por 78 organizaciones que participaron en el Foro Nacional de Jóvenes por los Derechos Sexuales realizado en Tlaxcala, México, en 2000 [6].

"El Estado debe respetar y apoyar mis decisiones sobre mi vida reproductiva, brindándome la información y servicios de salud que requiero, haciendo efectivo mi derecho a la confidencialidad." - Cartilla de los Derechos Sexuales de los y las Jóvenes, desarrollado durante la Campaña Nacional por los Derechos Sexuales de las y los Jóvenes: Hagamos un Hecho Nuestros Derechos, México, $2003[5]$.

La falta de educación escolar aumenta el riesgo de una deficiente salud reproductiva.

- Entre los varones, $42 \%$ de quienes tienen entre 13 y 19 años de edad y no asisten a la escuela ya han tenido relaciones sexuales, mientras que sólo $15 \%$ de quienes sí asisten a la escuela son sexualmente activos; $25 \%$ de las muchachas entre 13 y 19 años que no asisten a la escuela han tenido relaciones sexuales, mientras que sólo 3\% de las que sí asisten a la escuela las han tenido [3].

- Los hijos de madres con educación menor que la primaria suelen abandonar sus estudios y tener hijos a edades más tempranas [4] que los hijos de madres con más educación. Si esta tendencia no cambia, esta situación tenderá a perpetuarse.

- Mientras que $85 \%$ de las mujeres jóvenes que no terminaron la primaria conocen un método anticonceptivo, $99 \%$ de las que terminaron la secundaria conoce por lo menos uno de ellos [4].

La información, los servicios de salud reproductiva y el uso de métodos anticonceptivos para evitar el embarazo no deseado y las infecciones transmitidas sexualmente permiten que los y las jóvenes dispongan de tiempo para continuar con su educación, disfruten de mejores oportunidades de trabajo y se desarrollen antes de empezar una familia. Además de ayudarles a tener una vida sana, los y las jóvenes tienen el derecho a esta información:

"...Tengo derecho a una educación sexual sin prejuicios, que fomente la toma de decisiones libre e informada... Los contenidos sobre sexualidad en los programas educativos del Estado deben ser laicos y científicos, ser adecuados a las diferentes etapas de la juventud y contribuir a fomentar el respeto a la dignidad de las y los jóvenes." - Cartilla de los Derechos Sexuales de los y las Jóvenes, desarrollado durante la Campaña Nacional por los Derechos Sexuales de las y los Jóvenes: Hagamos un Hecho Nuestros Derechos, México, 2003 [5].

¿Qué hacer para apoyar el ejercicio de los derechos reproductivos de las y los jóvenes mexicanos?

Informar a la población joven sobre sus derechos y sobre los métodos, recursos y servicios que están a su alcance para lograr una mejor salud reproductiva.

Incluir a los y las jóvenes, específicamente, al momento de programar servicios de salud reproductiva dirigidos a ellos.

Incrementar el acceso de los y las jóvenes a servicios de salud reproductiva, incluyendo a las clínicas especializadas y farmacias amigables, asegurando que los proveedores estén capacitados adecuadamente para atender sus necesidades.

Mejorar el acceso a los anticonceptivos, incluyendo estrategias de bajo costo.

Disponer de presupuestos suficientes y transparentes que estén dirigidos específicamente a atender la salud reproductiva de los adolescentes.

- Fortalecer la educación sexual que se brinde en las escuelas, asegurando que los maestros hayan sido capacitados y que cuenten con información actualizada y basada en evidencias.

Difundir ampliamente el tema de derechos incluyéndolo en los cursos de formación de profesionales de la salud. 